\title{
KERJASAMA PIHAK SEKOLAH DAN PENGLIBATAN IBU BAPA INDIA DALAM PENDIDIKAN ANAK DI SEKOLAH KEBANGSAAN
}

\author{
(SCHOOL'S PARTNERSHIP AND INDIAN PARENTS' \\ INVOLVEMENT IN CHILD'S EDUCATION IN \\ NATIONAL SCHOOLS)
}

\author{
Suresh Kumar N Vellymalay \\ School of Distance Education, Universiti Sains Malaysia, \\ 11800 USM Pulau Pinang, Malaysia \\ E-mel: suresh@usm.my
}

Published date: 20 January 2017

To cite this article: Suresh Kumar N Vellymalay. (2016). Kerjasama pihak sekolah dan penglibatan ibu bapa India dalam pendidikan anak di sekolah kebangsaan. Asia Pacific Journal of Educators and Education, 31, 131-151. http://dx.doi.org/10.21315/ apjee2016.31.8

To link to this article: http://dx.doi.org/10.21315/apjee2016.31.8

\begin{abstract}
Abstrak: Kajian ini bertujuan untuk mengenal pasti kerjasama antara pihak sekolah dan ibu bapa dalam meningkatkan penglibatan ibu bapa India dalam pendidikan anak. Sebanyak 150 murid India yang sedang belajar di Sekolah Kebangsaan di daerah Kerian, Perak Darul Ridzuan dipilih menggunakan persampelan rawak berlapis. Sampel ini terdiri daripada 50 murid dari Tahun Tiga, 50 murid dari Tahun Empat dan 50 murid dari Tahun Lima. Soal selidik telah digunakan oleh penyelidik untuk memperoleh data kuantitatif daripada ibu bapa murid berkaitan dengan kerjasama pihak sekolah-ibu bapa dan strategistrategi penglibatan ibu bapa dalam pendidikan anak mereka. Hasil kajian menunjukkan bahawa terdapat hubungan yang signifikan dalam kerjasama pihak sekolah-ibu bapa dalam meningkatkan penglibatan ibu bapa India dalam pendidikan anak mereka. Lebih tinggi ibu bapa berasa bahawa kedatangan mereka ke sekolah dihargai oleh pihak sekolah, lebih tinggi pula penglibatan mereka dalam pendidikan anak. Ibu bapa juga menunjukkan penglibatan yang lebih tinggi dalam pendidikan anak apabila pihak sekolah bekerjasama dalam membincangkan hal-hal berkaitan anak mereka. Tambahan lagi, hasil kajian juga menunjukkan bahawa ibu bapa menunjukkan penglibatan yang lebih tinggi dalam pendidikan anak apabila ibu bapa terus dimaklumkan tentang mesyuaratmesyuarat, aktiviti-aktiviti dan program-program yang perlu dihadiri oleh ibu bapa di sekolah.
\end{abstract}


Kata kunci: penglibatan ibu bapa, kerjasama sekolah-ibu bapa, pendidikan anak, Sekolah Kebangsaan

\begin{abstract}
This study was designed to identify the relationship between school-parents partnership in enhancing Indian parents' involvement in their child's education. A 150 Indian students who were studying in National Schools in the district of Kerian, Perak Darul Ridzuan were randomly chosen based on stratified random sampling. The sample comprised 50 students from Year Three, 50 students from Year Four and 50 students from Year Five. Questionnaires were used by the researcher to obtain quantitative data from the parents related to the school-parents partnership and the parents' involvement strategies implemented for their child's education. Findings of this study indicated a significant relationship in school-parents partnership in enhancing Indian parents' involvement in their child's education. The more the parents feel welcomed at school, the higher their involvement in their child's education. The parents were also showed higher involvement when the school is cooperative in discussing matters pertaining to their child. In addition, findings also indicated that parents were more involved in their child's education when the parents were kept informed about the meetings, activities and events that have to be attended by parents at school.
\end{abstract}

Keywords: parental involvement, school-parent partnership, education, National School

\title{
PENGENALAN
}

Penglibatan ibu bapa dalam pendidikan anak bukan merupakan suatu isu baru yang menjadi bahan perdebatan dalam kajian-kajian pendidikan. Namun demikian, penglibatan ibu bapa dalam pendidikan anak di rumah dan juga di sekolah tidak semestinya dipengaruhi oleh kesedaran ibu bapa semata-mata untuk melibatkan diri dalam pendidikan anak. Hal ini kerana peranan sekolah juga merupakan suatu faktor penting dalam mendorong penglibatan ibu bapa dalam pendidikan anak. Akan tetapi, terdapat sesetengah sekolah yang memperlihatkan suatu bentuk kekosongan dalam hubungan antara pihak sekolah dan ibu bapa yang memberi kesan ke atas pola pembelajaran dan perkembangan anak (Epstein, 1995). Perbezaan pendapat antara ibu bapa dan guru mudah merenggangkan hubungan antara kedua-dua pihak tersebut. Kebanyakan guru berpendapat bahawa kanak-kanak terutamanya daripada kelas bawahan gagal mempelajari sesuatu kerana persekitaran rumah yang kurang selesa (Ogbu, 1974). Selain itu, guru juga sering menghadapi masalah dengan ibu bapa. Ibu bapa dikatakan tidak menghargai kebolehan dan kemahiran seseorang guru selain tidak dapat membezakan antara kepentingan hubungan dalam keluarga dan keperluan hubungan dengan pihak sekolah (Lightfoot, 1978).

Begitu juga dalam kalangan sesetengah ibu bapa yang memperlihatkan kelebaran jurang hubungan interaksi dengan pihak sekolah. Masalah ini disebabkan oleh 
latar belakang sosioekonomi ibu bapa dan persepsi negatif mereka terhadap pihak sekolah. Justeru, perbezaan pemikiran dan persepsi antara ibu bapa dan guru ini mampu memberi limitasi ke atas pola penglibatan ibu bapa terhadap pendidikan anak (Smrekar \& Cohen-Vogel, 2001). Maka, hubungan dan interaksi antara ibu bapa dan pihak sekolah sewaktu peringkat awal persekolahan anak amat penting memandangkan tahap-tahap awal pembelajaran yang dilakukan oleh anak ini dapat menjadi asas kepada tingkah laku, kualiti hubungan dan pelbagai jenis penglibatan ibu bapa pada tahun-tahun kemudiannya (Lightfoot, 1978). Sehubungan itu, penglibatan ibu bapa yang lebih berkesan dalam pendidikan anak akan menjadi lebih berkesan jika wujudnya hubungan kerjasama yang konkrit dan efektif dengan pihak sekolah.

Rata-rata kajian membuktikan bahawa latar belakang ibu bapa mempengaruhi penglibatan ibu bapa dalam pendidikan anak. Malah, penglibatan ibu bapa daripada latar belakang sosioekonomi atau kelas sosial yang tinggi adalah lebih kuat dalam menjamin pola pembelajaran dan dan kejayaan anak di sekolah. Dapatan kajian tersebut tidak dinafikan kebenarannya namun pengaruh latar belakang ibu bapa tidak semestinya dilihat sebagai satu-satunya faktor yang mendorong penghasilan kejayaan seseorang anak dalam pendidikan yang dikecapi. Penglibatan ibu bapa dalam pendidikan anak juga perlu dilihat dari pelbagai dimensi khususnya peranan pihak sekolah sebagai faktor pendorong penglibatan ibu bapa dalam pendidikan anak.

\section{KAJIAN LEPAS}

Hasil tinjauan literatur mendapati bahawa banyak kajian yang pernah dilakukan dalam ruang lingkup sosiologi pendidikan memberi tumpuan kepada penglibatan ibu bapa di rumah (Baker \& Stevenson, 1986; Entwisle \& Hayduk, 1981; Ho-Sui Chu \& Willms, 1996; Israel, Beaulieu, \& Hartless, 2001; Lockheed, Fuller, \& Nyirogo, 1989) dan di sekolah (Baker \& Stevenson, 1986; Epstein, 1995; Grolnick \& Slowiaczek, 1994; Hill, 2001; Hill \& Craft, 2003; Lareau, 1987; Milne, Myers, Rosenthal, \& Ginsburg, 1986; Ramsay, Harold, Hawk, Marriot, \& Poskitt, 1992; Reay, 2004; Rogers, Theule, Ryan, \& Adams, 2009). Kajian-kajian ini membuktikan bahawa terdapat hubungan yang signifikan dan positif antara penglibatan ibu bapa dan pencapaian pendidikan anak di sekolah.

Kajian-kajian tentang penglibatan dan kerjasama ibu bapa di sekolah memaparkan penglibatan ibu bapa sebagai faktor penting dalam kejayaan pendidikan anak (Kim, 2009). Misalnya, menurut kajian Lareau (1987) misalnya, ibu bapa kelas menengah melihat hubungan kerjasama antara ibu bapa dan guru sebagai salah satu faktor yang mempengaruhi kejayaan pendidikan anak mereka di sekolah. Kajian Ho Sui-Chu dan Willms (1996) mendapati bahawa komunikasi 
yang dilakukan oleh ibu bapa kelas menengah dengan pihak sekolah dan penglibatan yang ditunjukkan oleh ibu bapa tersebut di sekolah menjamin kejayaan pendidikan anak.

Selain itu, kajian-kajian juga membuktikan bahawa penglibatan ibu bapa di sekolah membawa pelbagai kebaikan kepada ibu bapa itu sendiri. Sebagai contoh, kajian Reay (2004) mendapati penglibatan ibu daripada kelas menengah dalam pendidikan anak membolehkan mereka sering mendapat maklum balas daripada pihak sekolah melalui sesi dialog apabila wujud ketegangan antara rumah-sekolah. Golongan ini juga berkeupayaan menolak cadangan yang tidak rasional di peringkat sekolah. Kajian Baker dan Stevenson (1986) pula mendapati penglibatan yang tinggi di sekolah dalam kalangan ibu yang berpendidikan lebih membolehkan mereka menghubungi pihak sekolah dengan kerap, mengetahui pencapaian anak, memantau kemajuan anak dan memimpin anak ke peringkat pengajian tinggi. Kajian Ramsay et al. (1992) pula mendapati golongan kelas menengah yang melibatkan diri dalam pelbagai aktiviti sekolah berasa kedatangan mereka ke sekolah dihargai oleh pihak sekolah. Golongan ini juga lebih yakin pada diri dan tidak mempunyai perasaan rendah diri untuk melibatkan diri dalam pendidikan anak di sekolah.

Walau bagaimanapun, kajian-kajian yang dibincangkan di atas jelas membuktikan bahawa wujudnya pergantungan yang tinggi oleh ibu bapa terhadap pihak sekolah. Satu persoalan yang mungkin timbul di sini ialah pencapaian pendidikan seseorang anak tidak semestinya meningkat semata-mata dengan penglibatan yang ditunjukkan oleh ibu bapa di sekolah (Allen, 2008). Pada masa yang sama, hubungan antara ibu bapa dan pihak sekolah juga tidak seharusnya dilihat pada pergantungan ibu bapa kepada pihak sekolah sahaja. Ia juga perlu dilihat sebaliknya iaitu dari segi hubungan yang ditunjukkan oleh pihak sekolah terhadap ibu bapa. Penglibatan ibu bapa di sekolah seperti yang dibuktikan oleh kajian-kajian Baker dan Stevenson (1986), Ho-Sui Chu dan Willms (1996), Lareau (1987), Ramsay et al. (1992) dan Reay (1999; 2004) tidak mungkin berkesan tanpa usaha secara langsung daripada pihak sekolah. Penglibatan ibu bapa dalam pendidikan anak juga didapati meningkat apabila pihak sekolah mempunyai pandangan yang positif terhadap ibu bapa dan sanggup bekerjasama dengan mereka (Bauch \& Goldring, 2000; Griffith, 1998). Maka, peranan pihak sekolah sebagai faktor pendorong penglibatan ibu bapa dalam pendidikan anak perlu diberi tumpuan dalam kajian-kajian mengenai penglibatan ibu bapa dalam pendidikan anak.

Justeru, kerjasama yang diberikan oleh pihak sekolah kepada ibu bapa amat penting dalam mendorong penglibatan ibu bapa dalam pendidikan anak. Penglibatan ibu bapa ini meningkat apabila adanya sokongan dan kerjasama yang 
berkesan daripada pihak sekolah. Pihak sekolah berperanan dalam membentuk kerjasama dengan ibu bapa bagi mengukuhkan kesedaran ibu bapa terhadap kepentingan mereka untuk melibatkan diri dalam pendidikan anak. Sehubungan itu, lebih tinggi kerjasama yang diberikan oleh pihak sekolah kepada ibu bapa, lebih tinggi penglibatan yang bakal ditunjukkan oleh ibu bapa dalam menjamin kecemerlangan pendidikan anak mereka.

Sehubungan itu, beberapa pengkaji telah memberi perhatian kepada hubungan antara kerjasama pihak sekolah dan penglibatan ibu bapa dalam pendidikan anak. Sebagai contoh, kajian Bartel (2010) mendapati bahawa kerjasama yang ditunjukkan oleh pihak sekolah mendorong lebih banyak ibu bapa melibatkan diri dalam membantu pendidikan anak di rumah dan di sekolah. Fantuzzo, Tighe dan Childs (2000) pula mendapati bahawa kepelbagaian program yang dilaksanakan di sekolah memberi peluang kepada ibu bapa untuk melibatkan diri dalam pendidikan anak. Kekerapan hubungan dan komunikasi yang terbentuk antara pihak sekolah dan ibu bapa mendorong ibu bapa melibatkan diri dalam pelbagai aktiviti yang diadakan di sekolah. Kajian Hindin (2010) pula mendapati tingkah laku pihak sekolah mengaturkan pertemuan antara ibu bapa dan guru selain menghubungi ibu bapa melalui telefon dan melalui surat menjadi pemangkin kepada penglibatan ibu bapa dalam pendidikan anak di sekolah.

Menurut Allen (2008) pula, peranan pihak sekolah melalui kunjungan ke rumah pelajar bukan sahaja mewujudkan hubungan silaturahim antara ibu bapa dan pihak sekolah malah ia juga membolehkan pihak sekolah memahami corak pembelajaran yang dilakukan oleh pelajar di luar waktu persekolahan. Tindakan pihak sekolah sebegini memberi ruang kepada pihak sekolah untuk merancang strategi yang berkesan untuk mendorong penglibatan ibu bapa dalam pendidikan anak di rumah. Selain itu, kajian Anderson and Minke (2007) mendapati bahawa permintaan daripada guru kepada ibu bapa untuk melibatkan diri di sekolah mendorong mereka melibatkan diri dalam pendidikan anak bukan sahaja di rumah tetapi juga di sekolah. Ibu bapa mendapati diri mereka dihargai dan dihormati di sekolah menyebabkan ibu bapa tersebut terdorong untuk melibatkan diri dalam pendidikan anak di sekolah. Begitu juga dengan kajian Koutrouba, Antonopoulou, Tsitsas dan Zenakou (2009) yang mendapati interaksi dan komunikasi antara guru dan ibu bapa amat penting bagi para guru untuk memahami konteks penglibatan ibu bapa dalam pendidikan anak. Penglibatan yang ditunjukkan oleh ibu bapa di sekolah turut memberi kesan positif kepada persekolahan anak dan pencapaian pendidikan.

Selain itu, kajian Jeynes (2005), Simon (2004) dan Overstreet, Devine, Bevans dan Efreom (2005) turut membuktikan kesan positif penglibatan ibu bapa di sekolah hasil permintaan pihak sekolah untuk melibatkan diri dalam pendidikan 
anak di sekolah. Kajian Jeynes (2005) mendapati bahawa usaha pihak sekolah menyediakan pelbagai program khususnya untuk membolehkan ibu bapa melibatkan diri dalam pendidikan anak turut memberi kesan positif terhadap pencapaian pendidikan anak. Dalam hal ini, penglibatan ibu bapa yang tinggi mempengaruhi cara guru menilai pelajar dan ia memberi kesan positif ke atas kerjasama ibu bapa-guru yang wujud hasil pembentukan komunikasi antara mereka. Ibu bapa turut merasai penghargaan guru terhadap usaha ibu bapa. Kajian Simon (2004) pula mendapati pemakluman pihak sekolah kepada ibu bapa tentang peluang penglibatan secara sukarela selain keperluan menjana kewangan untuk sekolah mendorong penglibatan yang tinggi dalam kalangan ibu bapa dalam aktiviti-aktiviti yang diadakan di sekolah. Permintaan pihak sekolah kepada ibu bapa untuk melibatkan diri dalam aktiviti di sekolah menyebabkan ibu bapa berasa diri mereka dihargai dan membolehkan ibu bapa meletakkan kepercayaan yang tinggi terhadap usaha sekolah membantu pendidikan anak. Kajian Overstreet et al. (2005) pula mendapati kesediaan pihak sekolah untuk mendengar pandangan ibu bapa dan mengadakan aktiviti untuk ibu bapa mendorong penglibatan ibu bapa di sekolah. Dalam hal ini, peranan sekolah menyediakan iklim sekolah yang membolehkan ibu bapa berasa diri dihargai mendorong penglibatan ibu bapa di sekolah.

Tambahan lagi, kajian Zhao dan Akiba (2009) mendapati bahawa harapan tinggi yang diletakkan oleh pengetua sekolah terhadap ibu bapa untuk menyokong pendidikan anak di rumah membolehkan para pelajar mencapai kejayaan yang baik dalam satu-satu subjek. Harapan pengetua terhadap ibu bapa mendorong ibu bapa untuk menyokong pendidikan anak. Sokongan ini termasuk tingkah laku ibu bapa membantu anak mereka melengkapkan kerja rumah sekolah selain tingkah laku ibu bapa untuk berhubung dengan pihak sekolah untuk berbincang tentang masalah yang dihadapi oleh anak di rumah. Selain itu, kajian Lloyd-Smith and Baron (2010) pula berpendapat bahawa pengetua sekolah-sekolah yang kecil mempunyai lebih banyak masa dan tenaga untuk menggerakkan usaha bagi melibatkan ibu bapa dalam pendidikan anak berbanding pengetua sekolahsekolah yang besar yang mempunyai lebih banyak staf dan pelajar untuk diselia.

Epstein (1995) turut melihat penglibatan ibu bapa dalam pendidikan anak dari sudut kerjasama sekolah dan keluarga dalam memahami cara sekolah, keluarga dan komuniti berkongsi tanggungjawab dengan pelajar bagi menjamin kejayaan pendidikan mereka. Menurutnya, sekolah, keluarga mahupun komuniti tidak semestinya menyumbang kepada kejayaan pelajar namun aktiviti yang terhasil daripada kerjasama sekolah, keluarga dan komuniti mampu mengarah dan memotivasikan pelajar agar mereka mencapai kejayaan sendiri (Epstein, 1995). Maka, kerjasama yang ditunjukkan oleh pihak sekolah amat penting dalam mendorong ibu bapa pelajar untuk melibatkan diri dalam pendidikan anak masing-masing. 
Menurut Epstein (1995) lagi, kerjasama antara sekolah, keluarga dan komuniti bukan sahaja dapat memperbaiki program-program dan persekitaran sekolah, meningkatkan kemahiran dan kepemimpinan ibu bapa, menghubungkan ibu bapa dengan pihak sekolah dan komuniti malah kerjasama ini turut membantu kerjakerja guru. Lantaran itu, beliau melihat penglibatan ibu bapa dalam pendidikan anak dari sudut kerjasama sekolah dan keluarga dalam memahami cara sekolah, keluarga dan komuniti berkongsi tanggungjawab dengan pelajar bagi menjamin kejayaan pendidikan.

Berdasarkan kajian-kajian lepas yang dibincangkan di atas, jelas terbukti bahawa terdapat hubungan yang signifikan antara kerjasama yang diberikan oleh pihak sekolah kepada ibu bapa dan kesedaran ibu bapa untuk melibatkan diri dalam pendidikan anak di sekolah. Namun demikian, terdapat juga banyak kajian yang mendokumentasikan kegagalan hubungan kerjasama antara sekolah dan ibu bapa dengan mengenal pasti faktor-faktor yang menghalang pembentukan hubungan kerjasama antara sekolah dan ibu bapa. Sebagai contoh, kajian Smrekar dan Cohen-Vogel (2001) mendapati bahawa ketiadan interaksi yang berkesan antara ibu bapa dan guru menyebabkan masalah pendidikan anak di sekolah tidak diketahui oleh ibu bapa di rumah. Hal ini menjejaskan penglibatan ibu bapa dalam pendidikan anak. Kajian Halsey (2005) mendapati bahawa penglibatan ibu bapa di sekolah bergantung kepada paten tradisional seperti menghadiri aktiviti, sukan dan konsert. Menurut beliau, penglibatan ibu bapa dalam bilik darjah menerusi polisi pintu terbuka yang membolehkan ibu bapa berkunjung ke sekolah untuk mengenal pasti masalah disiplin dan akademik anak masih terhad. Selain itu, kesukaran untuk mengimplementasikan kaedah komunikasi yang efektif yang dapat menghubungkan sekolah dengan ibu bapa turut menghalang penglibatan ibu bapa dalam pendidikan anak di sekolah. Tambahan lagi, kajian Halsey (2005) juga mendapati persepsi yang berbeza antara guru dan ibu bapa tentang bantuan dan keperluan untuk penglibatan ibu bapa turut menjadi penghalang penglibatan ibu bapa di sekolah. Maka, kegagalan komunikasi antara sekolah dan ibu bapa menjadi salah satu penghalang utama penglibatan ibu bapa dalam pendidikan anak di sekolah.

Kajian Kessler-Sklar dan Baker (2000) mendapati cabaran-cabaran yang wujud dalam menggendalikan program-program penglibatan ibu bapa turut memberi kesan ke atas penglibatan ibu bapa di sekolah. Kajian ini mendapati walaupun pihak sekolah menyediakan program bagi membenarkan ibu bapa membuat keputusan bagi meningkatkan kemajuan sekolah namun hanya segelintir yang berfungsi sebagai pembuat keputusan melalui jawatankuasa yang ditubuhkan. Selain itu, walaupun sekolah menyediakan program untuk menyokong polisi komunikasi dengan ibu bapa namun ekspektasi ibu bapa pada dasarnya adalah lebih daripada khidmat yang disediakan. Justeru, hal ini menghalang penglibatan ibu bapa secara menyeluruh. Kajian Ji dan Koblinsky (2009) ke atas ibu bapa 
yang merupakan migran China di Amerika pula mendapati bahawa faktor bahasa menghalang penglibatan ibu bapa dalam pendidikan anak di sekolah. Penguasaan dalam bahasa ibunda dan kekurangan kemahiran dalam bahasa Inggeris menyebabkan mereka tidak memahami dan tidak dapat berkomunikasi dalam bahasa Inggeris. Masalah ini menghalang hubungan mereka dengan pihak sekolah selain penglibatan mereka dalam PIBG di sekolah.

Dalam konteks Malaysia, kajian-kajian yang memberi keutamaan dalam menilai kerjasama yang diberikan oleh pihak sekolah dalam memupuk kesedaran ibu bapa untuk melibatkan diri dalam pendidikan anak masih dipersoalkan bilangannya. Tambahan lagi, kajian-kajian yang memfokuskan etnik minoriti dan isu pendidikan juga masih kurang bilangannya. Justeru, kajian ini bertujuan untuk menerangkan hubungan antara kerjasama pihak sekolah dan penglibatan ibu bapa etnik India dalam pendidikan anak mereka di Sekolah Kebangsaan.

\section{METODOLOGI KAJIAN}

\section{Sampel Kajian}

Sampel kajian ini terdiri daripada 150 ibu bapa murid. Untuk mendapatkan 150 ibu bapa ini, sebanyak 150 orang murid dipilih secara rawak iaitu mengikut persampelan rawak berlapis daripada jumlah 194 murid India di Sekolah Kebangsaan di daerah Kerian, Perak Darul Ridzuan. Murid-murid yang berada di Tahun Tiga hingga Tahun Lima iaitu 50 orang murid dari setiap Tahun dipilih dengan menggunakan Jadual Nombor Rawak. Dalam kajian ini, murid-murid Tahun Satu dan Tahun Dua tidak dipilih kerana ia terlalu awal untuk memantau penglibatan ibu bapa dalam pendidikan anak yang berada pada tahap awal persekolahan. Murid-murid Tahun Enam pula tidak dipilih kerana peraturan ditetapkan oleh Kementerian Pelajaran Malaysia agar kajian tidak dilakukan ke atas murid-murid yang bakal menduduki peperiksaan Ujian Penilaian Sekolah Rendah (UPSR). Daripada jumlah 150 orang murid tersebut, salah seorang sama ada ibu atau bapa bagi setiap murid dipilih (atas pandangan anak tentang individu yang paling banyak meluangkan masa bersamanya dalam membantu pendidikannya) untuk dijadikan responden kajian bagi sampel ibu bapa ini.

\section{Instrumen Kajian}

Soal selidik digunakan oleh pengkaji untuk mendapatkan data kuantitatif daripada sampel yang dikaji. Soal selidik ini diadaptasikan oleh pengkaji berdasarkan Walker, Wilkins, Dallaire, Sandler dan Hoover-Dempsey (2005). Namun, pengkaji telah melakukan modifikasi terhadap strukturnya dengan 
menambahkan soalan yang perlu dan menyingkirkan soalan-soalan yang dirasakan kurang penting untuk kajian ini selain membuat sedikit perubahan pada format responnya. Dalam kajian ini, perkara yang menjadi ukuran penglibatan ibu bapa terhadap pendidikan anak dalam soal selidik yang dikemukakan kepada salah seorang sama ada ibu atau bapa murid-murid Sekolah Kebangsaan merangkumi tiga komponen utama iaitu Latar Belakang Ibu Bapa, Kerjasama Pihak Sekolah dan Penglibatan Ibu Bapa dalam pendidikan anak.

Bahagian Latar Belakang Ibu Bapa dalam soal selidik merangkumi soalan-soalan tentang latar belakang ibu bapa yang dikaji dan kedudukan sosioekonomi mereka. Soalan-soalan latar belakang ini dijuruskan kepada jantina, umur, status perkahwinan dan tempat tinggal. Pertanyaan juga meliputi taraf pendidikan, pekerjaan, pendapatan, pendapatan isi rumah, bilangan tanggungan dalam keluarga dan bilangan anak yang bersekolah juga menjadi skop utama soalan yang akan diajukan kepada pelajar. Soalan-soalan yang diajukan dalam bahagian Kerjasama Pihak Sekolah merupakan enam soalan yang mengukur kerjasama yang ditunjukkan oleh pihak sekolah kepada ibu bapa. Antara soalan yang ditanya pada bahagian ini adalah seperti "Pihak sekolah menghargai kedatangan saya ke sekolah" dan "Pihak sekolah mengadakan aktiviti pada waktu yang sesuai untuk saya hadiri". Bagi setiap soalan dalam kategori Kerjasama Pihak Sekolah dalam soal selidik, responden diminta untuk menyatakan tahap kerjasama yang ditunjukkan oleh pihak sekolah kepada ibu bapa sama ada 'sangat rendah', 'rendah', 'sederhana', 'tinggi' dan 'sangat tinggi'. Soalan-soalan yang diajukan dalam bahagian Penglibatan Ibu Bapa dalam pendidikan anak pula adalah meliputi empat belas soalan yang mengukur keberkesanan pelbagai strategi yang dilakukan oleh ibu bapa untuk melibatkan diri dalam pendidikan anak. Soalansoalan yang diajukan adalah merangkumi soalan-soalan seperti "Saya membantu kerja rumah anak saya yang diberikan oleh pihak sekolah", "Saya menghubungi pihak sekolah untuk mengetahui corak pembelajaran yang dilakukan oleh anak saya di sekolah" dan "Saya membimbing anak saya sebagai persediaan menghadapi peperiksaan". Bagi setiap soalan dalam kategori Penglibatan Ibu Bapa dalam pendidikan anak dalam soal selidik, responden juga diminta untuk menyatakan tahap penglibatan ibu bapa sama ada 'sangat rendah', 'rendah', 'sederhana', 'tinggi' dan 'sangat tinggi'.

\section{Kaedah Kajian}

Kajian ini merupakan kajian kuantitatif menggunakan soal selidik sebagai instrumen kajian. Berdasarkan pemilihan sampel, surat pemakluman tentang kajian dikeluarkan kepada kesemua 150 responden kajian. Surat ini disampaikan kepada responden kajian melalui anak masing-masing. Sebanyak 150 responden yang terdiri daripada ibu bapa telah diminta untuk hadir ke sekolah pada tarikh 
dan waktu yang ditetapkan untuk melibatkan diri dalam kajian. Dalam surat tersebut, responden kajian dimaklumkan tentang objektif kajian dan juga kepentingan kerjasama mereka untuk melibatkan diri dalam kajian tersebut. Responden kajian juga dimaklumkan bahawa mereka tidak perlu melibatkan diri dalam kajian yang dilakukan ini jika tidak berminat.

Kesemua 150 responden mengambil bahagian dalam kajian ini. Setiap responden yang terlibat dalam kajian ini dijamin agar semua maklumat diri mereka dalam sesi temu bual ini akan dirahsiakan. Kesemua soalan dalam soal selidik dibentuk dalam bahasa Malaysia. Oleh sebab terdapat responden yang tidak dapat memahami bahasa Malaysia dengan jelas maka pengkaji terpaksa menterjemah soalan-soalan dalam soal selidik tersebut secara lisan ke dalam bahasa Tamil dan dibacakan kepada responden untuk membolehkan mereka mengisi maklumat yang diperlukan dan menandakan jawapan pada skala yang disediakan. Setiap soal selidik yang dikendalikan dengan responden mengambil masa lebih kurang 20-30 minit.

Semua maklumat yang diperoleh daripada responden melalui soal selidik dianalisis dengan menggunakan Statistical Package of Social Sciences (SPSS). Kesemua enam item dalam soal selidik bagi kategori 'kerjasama pihak sekolah' adalah konsisten. Nilai Cronbach alfanya adalah 0.78. Selain itu, kesemua empat belas item dalam kategori 'penglibatan ibu bapa' adalah juga konsisten dengan nilai Cronbach alfanya sebanyak 0.93. Kedua-dua angka ini menunjukkan bahawa ukuran bagi item-item yang dikaji ini mempunyai nilai kebolehpercayaan yang tinggi.

\section{DAPATAN KAJIAN}

Bahagian pertama dalam dapatan kajian menerangkan latar belakang ibu bapa yang dikaji. Bahagian kedua menerangkan analisis deskriptif tentang kerjasama yang ditunjukkan oleh pihak sekolah terhadap ibu bapa yang dapat merangsang penglibatan ibu bapa dalam pendidikan anak. Bahagian ketiga pula menerangkan analisis deskriptif tentang penglibatan ibu bapa dalam pendidikan anak. Bahagian terakhir dalam dapatan kajian ini pula menerangkan analisis korelasi antara kerjasama pihak sekolah dan penglibatan ibu bapa dalam pendidikan anak.

Jadual 1 menunjukkan pemboleh ubah-pemboleh ubah terpilih berkaitan latar belakang ibu bapa yang dikaji iaitu dari segi jantina, umur, tempat tinggal, taraf pendidikan, pekerjaan dan pendapatan. Seperti yang ditunjukkan dalam Jadual 1, golongan ibu mewakili $80.7 \%$ responden dan didapati paling banyak meluangkan masa bersama anak dalam membantu pendidikan anaknya berbanding golongan 
bapa. Hal ini membuktikan bahawa para ibu memikul tanggungjawab yang besar dalam membantu pendidikan anak dan memperlihatkan penglibatan yang tinggi dalam pendidikan anak berbanding golongan bapa. Dalam konteks ini, golongan ibu merupakan sumber sokongan utama bagi asuhan seseorang anak dari awal kelahiran dalam memenuhi segala keperluan pembangunan diri dan juga keperluan pendidikan di rumah.

Jadual 1. Latar belakang ibu bapa murid Sekolah Kebangsaan $(n=150)$

\begin{tabular}{llc}
\hline Latar belakang & & Peratus (\%) \\
\hline Jantina & Lelaki & 19.3 \\
& Perempuan & 80.7 \\
Umur & 30 tahun ke bawah & 15.3 \\
& $31-40$ tahun & 52.0 \\
& $41-50$ tahun & 29.3 \\
Tempat tinggal & 51-60 tahun & 3.3 \\
& Bandar & 79.3 \\
Taraf pendidikan & Luar bandar & 20.7 \\
& Tiada pendidikan formal & 4.7 \\
& Tamat sekolah rendah & 14.0 \\
& Tidak tamat sekolah menengah & 26.0 \\
& Tamat sekolah menengah & 45.3 \\
& Sijil dan diploma & 5.3 \\
& Ijazah pertama & 4.0 \\
& Ijazah lanjutan & 0.7 \\
Pekerjaan & Professional/teknikal & 8.7 \\
& Pentadbiran/perkeranian & 4.7 \\
& Perkhidmatan & 5.3 \\
& Berniaga & 8.0 \\
& Buruh & 41.3 \\
& Tidak bekerja (suri rumah) & 32.0 \\
& Tiada & 32.0 \\
& RM1000 ke bawah & 47.3 \\
& RM1001-RM2000 & 12.7 \\
& RM2001-RM3000 & 5.3 \\
& RM3001-RM4000 & 1.3 \\
& RM4001 dan ke atas & \\
\hline & & \\
& &
\end{tabular}

Hasil kajian mendapati $67.3 \%$ ibu bapa yang dikaji berumur 40 tahun dan ke bawah. Dari segi lokasi sosialnya pula, majoriti ibu bapa $(79.3 \%)$ yang dikaji menetap di kawasan bandar. Selain itu, didapati bahawa $85.3 \%$ ibu bapa memiliki taraf pendidikan tingkatan lima dan ke bawah. Sebanyak $4.7 \%$ ibu bapa pula tidak menerima pendidikan formal. Hanya $10.0 \%$ ibu bapa yang berjaya memperoleh pendidikan tinggi iaitu pada peringkat sijil/diploma, ijazah dan 
ijazah lanjutan. Dari segi pekerjaan pula, hanya $26.7 \%$ ibu bapa menjawat jawatan dalam empat bidang utama yang lain iaitu bidang profesional dan teknikal, pentadbiran dan perkeranian, perkhidmatan dan perniagaan. Sebanyak 41.3\% ibu bapa yang dikaji bekerja sebagai buruh. Rata-rata mereka bekerja di kilang berdekatan dengan tempat tinggal. Kekurangan taraf pendidikan yang tinggi dalam kalangan ibu bapa menggagalkan usaha mereka menjawat pekerjaan yang lebih terjamin. Walau bagaimanapun, didapati sebanyak $32.0 \%$ responden yang dikaji merupakan golongan ibu yang berperanan sebagai suri rumah. Dalam menilai jumlah pendapatan yang diterima oleh ibu bapa yang dikaji, sebanyak $47.3 \%$ ibu bapa memperoleh pendapatan RM1000 ke bawah dan $18.0 \%$ pula berpendapatan antara RM1001-RM3000. Hanya $2.6 \%$ ibu bapa yang mempunyai pendapatan lebih daripada RM3000. Selainnya $32.0 \%$ ibu bapa tidak berpendapatan kerana mereka merupakan golongan wanita yang berperanan sebagai suri rumah. Dengan ini dapat dikatakan bahawa secara keseluruhannya ibu bapa yang dikaji berasal daripada latar belakang sosioekonomi yang rendah.

Jadual 2. Kerjasama yang ditunjukkan oleh pihak sekolah $(n=150)$

\begin{tabular}{lcccccc}
\hline Kerjasama pihak sekolah & $\begin{array}{c}\text { Sangat } \\
\text { rendah } \\
(\%)\end{array}$ & $\begin{array}{c}\text { Rendah } \\
(\%)\end{array}$ & $\begin{array}{c}\text { Sederhana } \\
(\%)\end{array}$ & $\begin{array}{c}\text { Tinggi } \\
(\%)\end{array}$ & $\begin{array}{c}\text { Sangat } \\
\text { tinggi } \\
(\%)\end{array}$ & Min \\
\hline Menghargai kedatangan & 1.3 & 2.0 & 14.0 & 48.0 & 34.7 & 4.13 \\
$\begin{array}{l}\text { Perhatian dalam bincang } \\
\text { pendidikan anak }\end{array}$ & 4.7 & 5.3 & 16.7 & 41.3 & 32.0 & 3.91 \\
$\begin{array}{l}\text { Pemakluman mesyuarat } \\
\text { dan aktiviti }\end{array}$ & 2.7 & 4.7 & 16.7 & 45.4 & 30.7 & 3.97 \\
$\begin{array}{l}\text { Kesesuaian waktu aktiviti } \\
\text { Pemakluman masalah anak }\end{array}$ & 6.7 & 12.0 & 28.7 & 34.7 & 18.0 & 3.45 \\
Maklumat kemajuan & 7.3 & 14.7 & 30.7 & 26.7 & 20.7 & 3.39 \\
& 8.0 & 13.3 & 20.7 & 40.7 & 17.3 & 5.46 \\
\hline
\end{tabular}

Jadual 2 menunjukkan analisis deskriptif tentang kerjasama yang ditunjukkan oleh pihak sekolah yang dapat merangsang penglibatan ibu bapa dalam pendidikan anak. Berdasarkan Jadual 2, nilai min bagi setiap pemboleh ubah dalam kategori Kerjasama Pihak Sekolah adalah lebih daripada 3.0. Nilai ini jelas menunjukkan bahawa kerjasama yang ditunjukkan oleh pihak sekolah kepada ibu bapa adalah memberangsangkan. Tingkah laku pihak sekolah menghargai kedatangan ibu bapa ke sekolah menunjukkan nilai min sebanyak 4.13. Kerjasama pihak sekolah memaklumkan semua mesyuarat dan aktivitiaktiviti yang perlu hadiri oleh ibu bapa di sekolah anaknya menunjukkan nilai min sebanyak 3.97. Nilai min bagi kerjasama yang ditunjukkan oleh pihak sekolah dalam memberikan perhatian yang tinggi dalam membincangkan pendidikan anaknya dan kerjasama pihak sekolah dalam menyampaikan maklumat tentang kemajuan anak dalam pendidikan kepada ibu bapa dari semasa 
ke semasa pula adalah 3.91 dan 3.46 masing-masing. Nilai min bagi kerjasama pihak sekolah dalam mengadakan aktiviti pada waktu yang sangat sesuai untuk dihadiri oleh ibu bapa pula adalah sebanyak 3.45 manakala kerjasama pihak sekolah dalam menghubungi ibu bapa untuk memaklumkan sebarang masalah berhubung anaknya di sekolah pula adalah sebanyak 3.39.

Jadual 3. Penglibatan ibu bapa untuk melibatkan diri dalam pendidikan anak $(n=150)$

\begin{tabular}{lcccccc}
\hline Penglibatan ibu bapa & $\begin{array}{c}\text { Sangat } \\
\text { rendah } \\
(\%)\end{array}$ & $\begin{array}{c}\text { Rendah } \\
(\%)\end{array}$ & $\begin{array}{c}\text { Sederhana } \\
(\%)\end{array}$ & $\begin{array}{c}\text { Tinggi } \\
(\%)\end{array}$ & $\begin{array}{c}\text { Sangat } \\
\text { tinggi } \\
(\%)\end{array}$ & Min \\
\hline $\begin{array}{l}\text { Berbincang tentang masa depan } \\
\text { anak }\end{array}$ & 1.3 & 7.3 & 5.3 & 36.0 & 50.0 & 4.26 \\
Perbincangan aktiviti sekolah & 0.7 & 7.3 & 5.3 & 46.0 & 40.7 & 4.19 \\
Mengetahui corak pembelajaran & 1.3 & 10.0 & 16.0 & 42.0 & 30.7 & 3.91 \\
Mengenalpasti masalah & 3.3 & 10.0 & 9.3 & 40.7 & 36.7 & 3.97 \\
akademik di sekolah & & & & & & \\
Mengenalpasti masalah & 0.7 & 6.7 & 10.0 & 35.3 & 47.3 & 4.22 \\
akademik di rumah & & & & & & \\
Membantu kerja rumah & 4.0 & 15.3 & 9.3 & 34.0 & 37.3 & 3.85 \\
Mengenalpasti kerja rumah & 1.3 & 6.7 & 15.3 & 38.0 & 38.7 & 4.06 \\
Membimbing peperiksaan & 1.3 & 10.0 & 18.7 & 36.7 & 33.3 & 3.91 \\
Memantau peperiksaan & 1.3 & 8.0 & 15.3 & 36.7 & 38.7 & 4.03 \\
Menyuntik motivasi & 0.7 & 6.0 & 9.3 & 32.7 & 51.3 & 4.28 \\
Limitasi masa & 1.3 & 9.3 & 12.0 & 46.0 & 31.3 & 3.97 \\
Pembelian bahan bacaan & 3.3 & 8.0 & 16.0 & 32.0 & 40.7 & 3.99 \\
Pembekalan tuisyen & 8.7 & 15.3 & 9.3 & 26.0 & 40.7 & 3.75 \\
Pemantauan pergerakan & 2.0 & 10.7 & 6.7 & 38.7 & 42.0 & 4.08 \\
\hline
\end{tabular}

Jadual 3 menunjukkan analisis deskriptif tentang penglibatan ibu bapa dalam pendidikan anak. Berdasarkan Jadual 3, keseluruhannya nilai min dalam setiap pemboleh ubah dalam kategori Penglibatan Ibu Bapa menunjukkan bahawa penglibatan ibu bapa dalam pendidikan anak juga memberangsangkan. Daripada 14 pemboleh ubah, tujuh pemboleh ubah memperlihatkan nilai min antara 4.03 dan 4.28. Nilai min bagi penglibatan ibu bapa dalam menyuntik motivasi kepada anaknya untuk terus belajar dengan bersungguh-sungguh, berbincang dengan anak tentang masa depannya dan mengenal pasti masalah yang dihadapi oleh anaknya di rumah adalah masing-masing 4.28, 4.26 dan 4.22. Nilai min bagi penglibatan ibu bapa dalam berbincang tentang aktiviti-aktiviti yang dilakukan oleh anaknya di sekolah, memantau pergerakan anaknya di tempat-tempat lain (seperti pusat membeli-belah, padang permainan dan sebagainya) selain sekolah dan rumah, mengenal pasti kerja rumah yang diberikan oleh guru di sekolah dan 
memantau pencapaian peperiksaan anak dari semasa ke semasa adalah masingmasing sebanyak 4.19, 4.08, 4.06 dan 4.03. Tujuh pemboleh ubah lagi memperlihatkan nilai min antara 3.75 dan 3.99. Item-item ini merangkumi penglibatan ibu bapa dalam membelikan bahan bacaan tambahan (seperti surat khabar dan majalah) untuk anaknya dalam usaha meningkatkan prestasi pendidikan anaknya (3.99), memberi pengagihan masa yang terancang kepada anaknya untuk belajar, menonton dan bagi memenuhi aktiviti masa lapangnya (3.97), mengenal pasti masalah yang dihadapi oleh anaknya di sekolah dalam halhal yang berkaitan dengan akademik (3.97), mengetahui corak pembelajaran yang dilakukan oleh anaknya di sekolah (3.91), membimbing anak di rumah sebagai persediaan menghadapi peperiksaan (3.91), membantu kerja rumah anaknya yang diberikan oleh pihak sekolah (3.85) dan membekalkan tuisyen kepada anaknya untuk memperbaiki prestasi pendidikannya (3.75).

Jadual 4. Korelasi antara kerjasama pihak sekolah dan penglibatan ibu bapa untuk melibatkan diri dalam pendidikan anak $(n=150)$

\begin{tabular}{|c|c|c|c|c|c|c|}
\hline \multirow{2}{*}{ Penglibatan ibu bapa } & \multicolumn{6}{|c|}{ Kerjasama pihak sekolah } \\
\hline & $\operatorname{MK}(r)$ & $\mathrm{PK}(r)$ & $\operatorname{PMDA}(r)$ & $\mathrm{KWA}(r)$ & PMA $(r)$ & $\operatorname{MP}(r)$ \\
\hline $\begin{array}{l}\text { Berbincang tentang masa } \\
\text { depan anak }\end{array}$ & $0.42 * *$ & $0.59 * *$ & $0.43 * *$ & $0.24 * *$ & 0.04 & 0.12 \\
\hline $\begin{array}{l}\text { Perbincangan aktiviti } \\
\text { sekolah }\end{array}$ & $0.36 * *$ & $0.31 * *$ & $0.49 * *$ & 0.13 & 0.14 & -0.12 \\
\hline $\begin{array}{l}\text { Mengetahui corak } \\
\text { pembelajaran }\end{array}$ & $0.42 * *$ & $0.36 * *$ & $0.41 * *$ & $0.28 * *$ & $0.20 *$ & 0.11 \\
\hline $\begin{array}{l}\text { Mengenalpasti masalah } \\
\text { akademik di sekolah }\end{array}$ & $0.34 * *$ & $0.49 * *$ & $0.36^{* *}$ & $0.31 * *$ & 0.05 & 0.15 \\
\hline $\begin{array}{l}\text { Mengenalpasti masalah } \\
\text { akademik di rumah }\end{array}$ & $0.37 * *$ & $0.22 * *$ & $0.42 * *$ & $0.18 *$ & $0.16^{*}$ & 0.04 \\
\hline Membantu kerja rumah & $0.37 * *$ & $0.47 * *$ & $0.41 * *$ & $0.29 * *$ & 0.07 & 0.11 \\
\hline $\begin{array}{l}\text { Mengenalpasti kerja } \\
\text { rumah }\end{array}$ & $0.47 * *$ & $0.39 * *$ & $0.31 * *$ & $0.25 * *$ & $0.25 * *$ & $0.28 * *$ \\
\hline Membimbing peperiksaan & $0.56^{* *}$ & $0.47 * *$ & $0.24 * *$ & $0.24 * *$ & $0.24 * *$ & $0.28 * *$ \\
\hline Memantau peperiksaan & $0.43 * *$ & $0.35 * *$ & $0.29 * *$ & $0.20 *$ & $0.16^{*}$ & $0.29 * *$ \\
\hline Menyuntik motivasi & $0.43 * *$ & $0.42 * *$ & $0.45^{* *}$ & 0.12 & 0.07 & 0.04 \\
\hline Limitasi masa & $0.42 * *$ & $0.38 * *$ & $0.45^{* *}$ & $0.39 * *$ & 0.08 & 0.06 \\
\hline Pembelian bahan bacaan & $0.35^{* *}$ & $0.23 * *$ & $0.48^{* *}$ & $0.21 *$ & $0.18 *$ & 0.16 \\
\hline Pembekalan tuisyen & $0.38 * *$ & $0.44 * *$ & $0.40 * *$ & 0.15 & 0.06 & 0.19 \\
\hline Pemantauan pergerakan & $0.32 * *$ & $0.46^{* *}$ & $0.28 * *$ & $0.24 * *$ & -0.01 & 0.07 \\
\hline
\end{tabular}

Nota: MK-Menghargai kedatangan; PK-Perhatian berbincang pendidikan anak; PMDA-Pemakluman mesyuarat dan aktiviti; KWA-Kesesuaian waktu aktiviti; PMA-Pemakluman masalah anak; MP-Maklumat kemajuan; ** Korelasi signifikan pada tahap 0.01; * Korelasi signifikan pada tahap 0.05 
Jadual 4 menunjukkan analisis korelasi antara kerjasama yang ditunjukkan pihak sekolah dan penglibatan ibu bapa dalam pendidikan anak. Kerjasama yang ditunjukkan oleh pihak sekolah melalui pemboleh ubah Menghargai kedatangan, Perhatian berbincang pendidikan anak dan Pemakluman mesyuarat dan aktiviti rata-rata menampakkan hubungan yang signifikan dan positif ke atas penglibatan ibu bapa dalam pendidikan anak dalam kesemua 14 pemboleh ubah di bawah Penglibatan Ibu Bapa yang dikaji dengan nilai korelasi ( $r$ ) antara 0.32 dan 0.56 kecuali korelasi antara pemboleh ubah Perhatian berbincang pendidikan anak dengan pemboleh ubah Pembelian bahan bacaan $(r=0.23, p<0.01)$. Justeru, dapat dikatakan bahawa lebih tinggi pihak sekolah menghargai kedatangan ibu bapa ke sekolah, memberi perhatian dalam membincangkan pendidikan anak selain memaklumkan semua mesyuarat dan aktiviti-aktiviti yang perlu hadiri oleh ibu bapa di sekolah anaknya maka lebih tinggi lagi penglibatan yang ditunjukkan oleh ibu bapa dalam pelbagai strategi bagi merangsang pendidikan anak (rujuk Jadual 4).

Selain itu, kerjasama yang ditunjukkan oleh pihak sekolah melalui pemboleh ubah Kesesuaian waktu aktiviti pula menunjukkan hubungan yang signifikan dan positif ke atas sebelas pemboleh ubah di bawah kategori Penglibatan Ibu Bapa dalam pendidikan anak. Namun, hanya dua pemboleh ubah yang menunjukkan hubungan yang sederhana iaitu penglibatan ibu bapa dalam memberi pengagihan masa yang terancang kepada anaknya untuk belajar, menonton dan aktiviti masa lapangnya $(r=0.39, p<0.01)$ dan penglibatan ibu bapa dalam mengenal pasti masalah yang dihadapi oleh anaknya di sekolah dalam akademik $(r=0.31$, $p<0.01)$. Maka, lebih kerap pihak sekolah mengadakan aktiviti pada waktu yang sangat sesuai untuk dihadiri oleh ibu bapa, lebih tinggi penglibatan ibu bapa dalam memberi pengagihan masa yang terancang kepada anaknya untuk belajar, menonton dan aktiviti masa lapangnya selain mengenal pasti masalah yang dihadapi oleh anaknya di sekolah dalam akademik. Hal ini bermakna peluang bagi ibu bapa untuk menghadiri aktiviti yang diadakan di sekolah adalah tinggi jika pihak sekolah dapat mengadakan aktiviti tersebut pada waktu yang sesuai untuk dihadiri oleh ibu bapa. Melalui kehadiran dalam aktiviti, ibu bapa dapat pelbagai input untuk memantau pengurusan masa dan menegenalpasti masalah anak dalam pembelajaran.

\section{PERBINCANGAN DAN KESIMPULAN}

Walaupun status sosioekonomi ibu bapa memperlihatkan pengaruh ke atas penglibatan ibu bapa dalam pendidikan anak, namun ia tidak seharusnya dianggap sebagai satu-satunya faktor yang mendorong penglibatan ibu bapa dalam pendidikan anak. Hal ini kerana adakalanya penglibatan ibu bapa dalam pendidikan anak juga dipengaruhi pelbagai faktor luaran yang lain. Salah satu 
daripada faktor luaran yang merangsang ibu bapa untuk melibatkan diri dalam pendidikan anak ialah kerjasama yang diberikan oleh pihak sekolah ke atas ibu bapa. Kerjasama yang diberikan oleh pihak sekolah mampu mempengaruhi minda ibu bapa dan meningkatkan kesedaran mereka tentang keperluan untuk melibatkan diri dalam pendidikan anak agar anak tersebut berjaya mencapai keputusan yang cemerlang dalam peperiksaan di sekolah. Sehubungan itu, kajian ini menunjukkan bahawa lebih tinggi kerjasama diberikan oleh pihak sekolah, lebih tinggi lagi penglibatan ibu bapa dalam pendidikan anak. Kerjasama ibu bapa bukan sahaja membolehkan ibu bapa melibatkan diri dalam pendidikan anak di rumah dan di sekolah malah ia turut membolehkan ibu bapa melibatkan diri dalam memantau pendidikan anak di luar sekolah. Justeru, dapatan kajian ini adalah selaras dengan kajian Lareau (1987), Reay (2004), Baker dan Stevenson (1986), dan Ho Sui-Chu dan Willms (1996) yang jelas membuktikan bahawa terdapatnya hubungan yang signifikan dan positif antara kerjasama pihak sekolah dan penglibatan ibu bapa dalam pendidikan anak.

Hasil kajian ini juga jelas menyokong hujah Epstein (1995) yang menjelaskan bahawa kerjasama daripada pihak sekolah amat penting bagi merangsang penglibatan ibu bapa dalam pendidikan anak. Kerjasama daripada pihak sekolah memberi ruang kepada pelbagai program kerjasama yang diimplementasikan dalam usaha meningkatkan hubungan antara pihak sekolah dan ibu bapa. Melalui pembentukan hubungan yang baik antara pihak sekolah dan ibu bapa, kemahiran dan kepemimpinan ibu bapa dapat dipertajam agar golongan ini dapat berkongsi kepercayaan, peranan dan tanggungjawab mereka untuk melibatkan diri dalam pendidikan anak. Ibu bapa juga lebih terdedah kepada pelbagai strategi penglibatan terutamanya di rumah dan juga di sekolah hasil kerjasama yang lebih berkesan antara kedua-dua pihak ini demi menjamin pencapaian akademik anak tersebut.

Hasil kajian ini juga mendapati bahawa terdapat tiga tingkah laku pihak sekolah yang mendorong penglibatan ibu bapa dalam pendidikan anak. Tingkah laku pihak sekolah iaitu menghargai kunjungan ibu bapa ke sekolah, memberi perhatian dalam membincangkan pendidikan anak dan memaklumkan ibu bapa tentang mesyuarat dan aktiviti yang diadakan di sekolah merupakan tiga strategi kerjasama pihak sekolah yang telah meningkatkan penglibatan ibu bapa dalam pendidikan anak.

Tingkah laku pihak sekolah dalam menghargai kunjungan ibu bapa ke sekolah merupakan salah satu faktor asas yang penting bagi meraih penglibatan ibu bapa dalam pendidikan anak. Jika dilihat secara umum, kebiasaannya pelbagai kekurangan dalam latar belakang sosioekonomi ibu bapa iaitu dari segi taraf pendidikan, pekerjaan dan pendapatan sering memperlihatkan jurang perbezaan 
yang begitu ketara pada kedudukan dan status ibu bapa jika dibandingkan dengan kedudukan dan status pihak sekolah yang merupakan kelas menengah. Justeru, perbezaan sebegini akan mengakibatkan sifat rendah diri dan rasa tidak selesa dalam kalangan ibu bapa untuk berkunjung dengan pihak sekolah. Namun demikian, penghargaan yang diberikan oleh pihak sekolah atas kunjungan ibu bapa ke sekolah dapat menenggelamkan perasaan ini dalam kalangan ibu bapa. Dapatan kajian ini mendapati penghargaan yang diberikan oleh pihak sekolah kepada ibu bapa yang rata-ratanya daripada latar belakang sosioekonomi yang rendah menyebabkan ibu bapa berasa kehadiran mereka di sekolah dihargai. Hal ini menimbulkan keyakinan pada diri ibu bapa dan mengurangkan sifat rendah diri dan rasa tidak selesa dalam kalangan ibu bapa untuk berhubung dengan pihak sekolah. Selain itu, penghargaan yang ditunjukkan oleh pihak sekolah juga mampu mengelakkan prasangka terhadap pihak sekolah bahawa guru-guru mempunyai status yang tinggi dan tidak mahu melayani ibu bapa. Dapatan kajian ini juga jelas menunjukkan bahawa penghargaan pihak sekolah terhadap kunjungan ibu bapa ke sekolah dan perasaan ibu bapa tentang penghormatan yang diletakkan oleh pihak sekolah terhadap diri mereka merapatkan jurang perbezaan yang wujud antara ibu bapa dan pihak sekolah. Kekuatan hubungan antara ibu bapa dan pihak sekolah merangsang ibu bapa untuk melibatkan diri dalam pelbagai strategi pendidikan anak. Maka, hasil kajian ini didapati konsisten dengan kajian Anderson dan Minke (2007), Ramsay (1992) dan Overstreet et al. (2005) yang mengetengahkan bahawa penghargaan pihak sekolah sebagai faktor penting bagi penglibatan ibu bapa di sekolah.

Selain itu, perhatian yang ditunjukkan oleh pihak sekolah dalam membincangkan pendidikan anak membolehkan ibu bapa memahami peranan dan tanggungjawab pihak sekolah dengan lebih dekat lagi. Ia turut membolehkan ibu bapa memahami setiap usaha pihak sekolah dalam meningkatkan pencapaian pendidikan pelajarnya. Hasil kajian ini didapati konsisten dengan kajian Bartel (2010) dan Zhao dan Akiba (2009) yang mendapati kerjasama pihak sekolah yang mendorong ibu bapa melibatkan diri dalam pelbagai strategi pendidikan anak. Selain itu, perhatian yang ditunjukkan oleh pihak sekolah juga meningkatkan kepercayaan ibu bapa terhadap pihak sekolah dan membolehkan ibu bapa bergerak selaras tuntutan dan permintaan pihak sekolah kepada ibu bapa. Tingkah laku pihak sekolah ini merangsang ibu bapa untuk menilai kredibiliti diri dan keperluan mereka untuk membantu pendidikan anak bersama-sama menjayakan visi dan misi yang dilakukan oleh pihak sekolah. Pembentukan interaksi yang baik antara ibu bapa dan guru hasil perhatian yang ditunjukkan oleh pihak sekolah dalam membincangkan pendidikan anak membolehkan pelbagai masalah dalam pendidikan anak di sekolah diketahui oleh ibu bapa. Dapatan kajian ini walau bagaimanapun konsisten dengan kajian Halsey (2005), Koutrouba et al. (2009) dan Smrekar dan Cohen-Vogel (2001) yang mendapati kepentingan keperluan interaksi dan komunikasi antara ibu bapa dan guru bagi 
membolehkan ibu bapa mengetahui masalah pendidikan anak di sekolah dan seterusnya memahami keperluan untuk melibatkan diri dalam pendidikan anak. Dalam kajian ini, faktor bahasa tidak banyak memberi kesan kepada ibu bapa dalam membentuk interaksi dengan guru. Walaupun ibu bapa yang dikaji adalah daripada etnik India dan rata-rata mereka berurusan dengan guru berbangsa Melayu namun perbezaan bahasa komunikasi dan status sosioekonomi antara ibu bapa dan guru tidak memberi impak negatif dalam kerjasama yang diberikan oleh pihak sekolah dalam membincangkan pendidikan anak. Justeru, hasil kajian ini tidak konsisten dengan kajian Ji dan Koblinsky (2009) yang mendapati perbezaan bahasa komunikasi antara ibu bapa dan guru menghalang komunikasi antara mereka lalu memberi kesan negatif terhadap penglibatan ibu bapa dalam pendidikan anak.

Tambahan lagi, pemakluman pihak sekolah tentang mesyuarat dan aktivitiaktiviti yang diadakan di sekolah merupakan permintaan pihak sekolah secara simbolik kepada ibu bapa untuk memberikan kerjasama dan melibatkan diri dalam mesyuarat dan aktiviti-aktiviti yang diadakan di sekolah. Pemakluman ini membolehkan ibu bapa mudah mengenal pasti agenda-agenda yang mengambil tempat di sekolah. Tindakan pihak sekolah ini juga membolehkan ibu bapa berbincang dengan anak tentang aktiviti-aktiviti yang berlaku di sekolah dan mengenal pasti tahap penglibatan anak dalam aktiviti tersebut tidak kira dalam aktiviti kurikulum mahupun aktiviti kokurikulum. Ia juga membolehkan ibu bapa mengenal pasti tarikh-tarikh penting (misalnya, tarikh peperiksaan) agar mereka terus membimbing anak menghadapi peperiksaan dan memantau pencapaian anak secara berperingkat di sekolah. Pemakluman pihak sekolah tentang mesyuarat dan aktiviti-aktiviti sekolah pula memudahkan ibu bapa untuk memantau pergerakan anak selain di rumah dan di sekolah agar masa yang lapang tidak diluangkan untuk aktiviti-aktiviti tertentu yang tidak berfaedah. Begitu juga halnya dalam program-program yang dijalankan di sekolah memberi peluang kepada ibu bapa untuk melibatkan diri. Kajian ini konsisten dengan kajian Fantuzzo et al. (2000) dan Jeynes (2005) yang mendapati hubungan yang terbentuk dengan pihak sekolah mendorong ibu bapa melibatkan diri dalam pelbagai aktiviti ibu bapa yang diadakan di sekolah. Malah, konsisten dengan kajian Anderson dan Minke (2007), permintaan daripada guru untuk melibatkan diri di sekolah mendorong penglibatan ibu bapa dalam pendidikan anak di rumah dan juga di sekolah.

Walau bagaimanapun, kajian ini mempunyai beberapa limitasi. Pertama, hasil kajian ini hanya memfokuskan hubungan antara kerjasama pihak sekolah dan penglibatan ibu bapa dalam pendidikan anak tanpa mengambil kira latar belakang sosioekonomi ibu bapa. Oleh itu, kajian pada masa akan datang perlu dilakukan untuk menguji pengaruh kerjasama pihak sekolah ke atas penglibatan ibu bapa dalam pendidikan anak dengan mengambil kira status sosioekonomi ibu bapa. 
Kedua, kajian yang meneroka hubungan kerjasama antara pihak sekolah dan ibu bapa hanya difokuskan kepada satu kumpulan etnik sahaja. Kajian pada masa akan datang perlu memfokuskan perbandingan antara ketiga-tiga etnik utama yang terdapat di Malaysia iaitu etnik Melayu, Cina dan India. Kajian perbandingan sebegini mungkin memberi keputusan yang berbeza tentang kesan sikap dan tingkah laku pihak sekolah ke atas ibu bapa daripada pelbagai etnik ini dalam melibatkan diri dalam pendidikan anak. Ketiga, kajian ini hanya memfokuskan ibu bapa di Sekolah Kebangsaan semata-mata. Kajian perbandingan melibatkan Sekolah Kebangsaan, Sekolah Jenis Kebangsaan Cina dan Sekolah Jenis Kebangsaan Tamil juga kemungkinan memberi hasil yang lebih bermakna dalam menilai hubungan kerjasama antara pihak sekolah dan ibu bapa. Oleh itu, kajian ini ingin menarik perhatian kepada keperluan lebih banyak kajian dalam ruang lingkup kerjasama antara pihak sekolah dan ibu bapa.

\section{RUJUKAN}

Allen, J. (2008). Family partnerships that count. Educational Leadership, 66(1), 22-27.

Anderson, K. J., \& Minke, K. M. (2007). Parental involvement in education: Toward an understanding of parents' decision making. Journal of Educational Research, 100, 311-323. http://dx.doi.org/10.3200/JOER.100.5.311-323

Baker, D. P., \& Stevenson, D. L. (1986). Mothers' strategies for childrens's school achievement: Managing the transition to high school. Sociology of Education, 59 (July), 156-166. http://dx.doi.org/10.2307/2112340

Bartel, V. B. (2010). Home and school factors impacting parental involvement in a title I elementary school. Journal of Research in Childhood Education, 24(3), 209228. http://dx.doi.org/10.1080/02568543.2010.487401

Bauch, P. A., \& Goldring, E. B. (2000). Teacher work context and parent involvement in urban high schools of choice. Educational Research and Evaluation, 6(1), 1-23. http://dx.doi.org/10.1076/1380-3611(200003)6:1;1-I;FT001

Entwisle, D. R., \& Hayduk, L. A. (1981). Academic expectations and the school attainment of young children. Sociology of Education, 54(Jan), 34-50. http://dx.doi.org/10.2307/2112511

Epstein, J. L. (1995). School/family/community partnership: Caring for the children we share. Phi Delta Kappan, 76, 701-712.

Fantuzzo, J., Tighe, E., \& Childs, S. (2000). Family involvement questionnaire: A multivariate assessment of family participation in early childhood education. Journal of Educational Psychology, 92, 367-376. http://dx.doi.org/ 10.1037/0022-0663.92.2.367

Griffith, J. (1998). The relation of school structure and social environment to parent involvement in elementary schools. The Elementary School Journal, 99(1), 53 80. http://dx.doi.org/10.1086/461916

Grolnick, W., \& Slowiaczek, M. (1994). Parents' involvement in children's schooling: A multidimensional conceptualization and motivational model. Child Development, 65, 237-252. http://dx.doi.org/10.2307/1131378 
Halsey, P. A. (2005). Parent involvement in junior high schools: A failure to communicate. American Secondary Education, 34, 57-69.

Hildebrand, V. (1991). Introduction to early childhood education (6th ed.). New Jersey: Prentice Hall.

Hill, N. E. (2001). Parenting and academic socialization as they relate to school readiness: The roles of ethnicity and family income. Journal of Educational Psychology, 93, 686-697. http://dx.doi.org/10.1037/0022-0663.93.4.686

Hill, N. E., \& Craft, S. A. (2003). Parent-school involvement and school performance: Mediated pathways among socioeconomically comparable African American and Euro-American families. Journal of Educational Psychology, 95(1), 74-83. http://dx.doi.org/10.1037/0022-0663.95.1.74

Hindin, A. (2010). Linking home and school: Teacher candidates' beliefs and experiences. The School Community Journal, 20(2), 73-90.

Ho Sui-Chu, E., \& Willms, J. D. (1996). Effects of parental involvement on eight-grade achievement. Sociology of Education, 69(April), 126-141. http://dx.doi.org/ $10.2307 / 2112802$

Israel, G. D., Beaulieu, L. J., \& Hartless, G. (2001). The influence of family and community social capital on educational achievement. Rural Sociology, 66(1), 43-68. http://dx.doi.org/10.1111/j.1549-0831.2001.tb00054.x

Jeynes, W. H. (2005). A meta-analysis of the relation of parental involvement to urban elementary school student academic achievement. Urban Education, 40, 237269. http://dx.doi.org/10.1177/0042085905274540

Ji, C.S. \& Koblinsky, S. A. (2009). Parent involvement in children's education: An exploratory study of urban, Chinese immigrant families. Urban Education, 44(6), 687-709. http://dx.doi.org/10.1177/0042085908322706

Kessler-Sklar, S. L., \& Baker, A. J. (2000). School district parent involvement policies and programs. The Elementary School Journal, 101, 101-118. http://dx.doi.org/ $10.1086 / 499661$

Kim, Y. (2009). Minority parental involvement and school barriers: Moving the focus away from deficiencies of parents. Educational Research Review, 4, 80-102. http://dx.doi.org/10.1016/j.edurev.2009.02.003

Koutrouba, K., Antonopoulou, E., Tsitsas, G., \& Zenakou, E. (2009). An investigation of greek teachers' views on parental involvement in education. School Psychology International, 30(3), 311-328. http://dx.doi.org/10.1177/0143034309106497

Lareau, A. (1987). Social class differences in family-school relationships: The importance of cultural capital. Sociology of Education, 60(April), 73-85. http://dx.doi.org/10.2307/2112583

Lightfoot, S. L. (1978). Worlds apart. New York: Basic Books.

Lloyd-Smith, L., \& Baron, M. (2010). Beyond conferences: Attitudes of high school administrators toward parental involvement in one small midwestern state. The School Community Journal, 20(2), 23-44.

Lockheed, M. E, Fuller, B., \& Nyirogo, R. (1989). Family effects on students achievement in Thailand and Malawi. Sociology of Education, 62(October), 239-256. http://dx.doi.org/10.2307/2112829

Milne, A. M., Myers, D. E., Rosenthal, A. S., \& Ginsburg, A. (1986). Single parents, working mothers and the educational achievement of school children. Sociology of Education, 59 (July), 125-139. http://dx.doi.org/10.2307/2112335 
Ogbu, J. U. (1974). The next generation. New York: Academis Press.

Overstreet, S., Devine, J., Bevans, K., \& Efreom, Y. (2005). Predicting parental involvement in children's schooling within an economically disadvantaged African American sample. Psychology in the Schools, 42(1), 101-111. http://dx.doi.org/10.1002/pits.20028

Ramsay, P., Harold, B., Hawk, K., Marriot, R., \& Poskitt, J. (1992). Sharing curriculum decisions with parents: An overview of the findings of project C.R.R.I.S.P. New Zealand Journal of Educational Studies, 27(2), 167-181.

Reay, D. (1999). Making contacts with teachers: Habitus, cultural capital and mothers involvement in their children's primary schooling. In M. Grenfell, \& M. Kelly (Eds.). Pierre Bourdieu: Language, culture and education. Theory into practice (pp. 271-280). Germany: Peter Lang.

Reay, D. (2004). Education and cultural capital: The implications of changing trends in education policies. Cultural Trends, 13(2), No. 50, 73-86. http://dx.doi.org/ 10.1080/0954896042000267161

Rogers, M. A., Theule, J., Ryan, B. A., \& Adams, G. R. (2009). Parental involvement and children's school achievement: Evidence for mediating processes. Canadian Journal of School Psychology, 24(1), 34-57. http://dx.doi.org/10.1177/ 0829573508328445

Simon, B. (2004). High school outreach and family involvement. Social Psychology of Education, 7, 185-209. http://dx.doi.org/10.1023/B:SPOE.0000018559.47658. 67

Smrekar, C., \& Cohen-Vogel, L. (2001). The voices of parents: Rethinking the intersection of family and school. Peabody Journal of Education, 76(2), 75-100. http://dx.doi.org/10.1207/S15327930pje7602_5

Walker, J. M. T., Wilkins, A. S., Dallaire, J. R., Sandler, H. M., \& Hoover-Dempsey, K. (2005). Parental involvement: Model revision through scale Development. The Elementary School Journal, 106(2), 85-103. http://dx.doi.org/10.1086/499193

Zhao, H., \& Akiba, M. (2009). School expectations for parental involvement and student mathematics achievement: A comparative study of middle schools in the US and South Korea. Compare, 39(3), 411-428. http://dx.doi.org/10.1080/030579 20701603347 